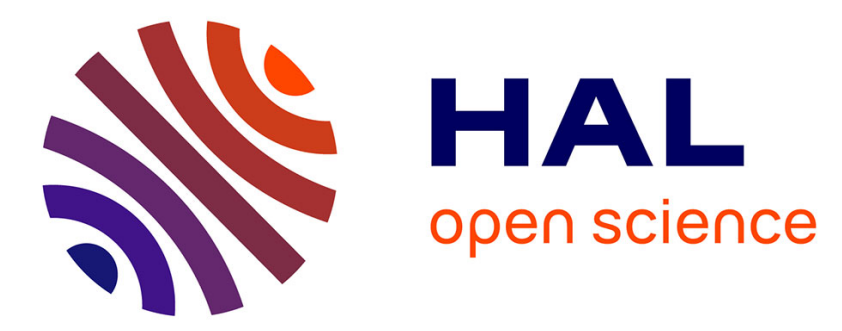

\title{
Exploring the redox reactivity of magnesium porphine. Insight into the origins of electropolymerisation
}

Charles H. Devillers, Dominique Lucas, Abdou K D Dime, Yoann Rousselin, Yves Mugnier

\section{- To cite this version:}

Charles H. Devillers, Dominique Lucas, Abdou K D Dime, Yoann Rousselin, Yves Mugnier. Exploring the redox reactivity of magnesium porphine. Insight into the origins of electropolymerisation. Dalton Transactions, 2010, 39 (9), pp.2404. 10.1039/b914916c . hal-03420006

\section{HAL Id: hal-03420006 https://hal.science/hal-03420006}

Submitted on 8 Nov 2021

HAL is a multi-disciplinary open access archive for the deposit and dissemination of scientific research documents, whether they are published or not. The documents may come from teaching and research institutions in France or abroad, or from public or private research centers.
L'archive ouverte pluridisciplinaire HAL, est destinée au dépôt et à la diffusion de documents scientifiques de niveau recherche, publiés ou non, émanant des établissements d'enseignement et de recherche français ou étrangers, des laboratoires publics ou privés. 


\title{
Exploring the redox reactivity of magnesium porphine. Insight into the origins of electropolymerisation $\uparrow$
}

\author{
Charles H. Devillers, ${ }^{* a}$ Dominique Lucas, ${ }^{a}$ Abdou K. D. Dime, ${ }^{a}$ Yoann Rousselin ${ }^{\text {a }}$ and Yves Mugnier ${ }^{a}$ \\ Received (in $X X X, X X X)$ Xth $X X X X X X X X X 200 X$, Accepted $X$ th $X X X X X X X X X 200 X$ \\ ${ }_{5}$ First published on the web Xth $X X X X X X X X X 200 X$ \\ DOI: 10.1039/b000000x
}

Magnesium(II) porphine, $\operatorname{MgP}(\mathbf{1})$, was synthesised according to the Lindsey procedure allowing to isolate and crystallise 1-formyldipyrromethane (2) as a synthetic intermediate. Unprecedented Xray diffraction studies revealed multiple intermolecular associations in the crystal between

10 neighbouring units of $\mathbf{2}$, namely hydrogen bond and $\mathrm{CH}^{\cdots} \pi$. The electrochemical behaviour of $\mathbf{1}$ was examined by means of cyclic voltammetry. In oxydation, two well-defined and distinct steps are assigned to macrocycle concerned electron transfers yielding initially the $\pi$-cation radical and $\pi$ dication, respectively. The highly reactive dication condenses neutral magnesium porphine to form a diprotonated di-isoporphine species, which is assumed to be a key intermediate at the origin of 15 the electropolymerisation. Electrolyses were performed at the potential of the $\pi$-cation radical generation. Investigation of the electrolysed solution by UV-visible spectroscopy and Maldi-tof spectrometry revealed the presence of several oligoporphyrins, with diporphine as an important product. In all the oligomers series, extensive demetallation is evidenced, due to the increasing acidity of the medium as oligomerisation progresses. This demetallation could be prevented by 20 addition of 2,6-lutidine as a base prior to electrolysis. In the oligomer series, the porphine units seem to be connected through meso-meso bonds, an argument supported by certain features of the UV-visible spectrum. Finally, the mechanism of oxidative oligomerisation is discussed, from the point of view of the initial steps of the electropolymerisation.

\section{Introduction}

${ }_{25}$ For many decades, porphyrins have been the subject of intense research in numerous areas such as artificial photosynthesis, molecular electronic devices, electrochemical sensors and electrocatalysis. ${ }^{1}$ The complexity of these macrocycle structures is continually increasing, as new specifically 30 designed fragments are added on the periphery of the porphyrin in the aim of developing multifunctional materials.

Conversely, the simplest porphyrin representative, called porphine, is of great fundamental interest. Porphine is a totally unsubstituted porphyrin with twelve free $\beta$ and meso 35 positions. Although several studies have been reported on free base and metallated porphine molecules (in the solid state ${ }^{2,3}$ or in solution ${ }^{3,4}$ ), the majority of such studies are theoretical due to the extreme structural simplicity of this macrocycle, requiring less power/memory for calculations. ${ }^{5}$ The relative 40 rarity of experimental studies dedicated to porphine or metalloporphine certainly stems from the poor commercial availability of this molecule. ${ }^{\ddagger}$ Indeed, until now, its synthesis was reputed to be awkward, with dissuasively poor yields. ${ }^{6}$ In addition, its solubility is very weak in common organic 45 solvents. However, an efficient and concise synthesis has recently been developed by Lindsey research group, leading in three steps to magnesium(II) porphine 1 ( MgP, overall yield starting from pyrrole: 17\%).,8 The latter exhibits good solubility in common organic solvents $\left(\mathrm{CHCl}_{3}, \mathrm{CH}_{2} \mathrm{Cl}_{2}\right.$, ${ }_{50} \mathrm{EtOAc}, \mathrm{EtOH}, \mathrm{MeOH}$, toluene, acetone, DMF, $\mathrm{CH}_{3} \mathrm{CN}$, $\left.\mathrm{Et}_{2} \mathrm{O} \ldots\right)$ and is even slighly soluble in $n$-hexane. The good solubility and availability of $\mathrm{MgP}$ offer the opportunity for comprehensive studies of its physico-chemical properties. Surprisingly, until now, the detailed study of the ${ }_{55}$ electrochemical behaviour of solute porphine or its metallated derivatives, particularly $\mathrm{MgP}$, has never been reported. Indeed, for 1, only the first oxidation potential and the experimental HOMO-LUMO gap (potential difference between the first oxidation and reduction) have been briefly 60 mentioned. ${ }^{9-11}$ The presence of the magnesium(II) ion in the porphine cavity is of particular interest in electrochemistry since magnesium insertion is known to drastically reduce the porphyrin redox potentials compared to free bases, providing an easier access to the oxidised states. ${ }^{12}$

65 Bearing in mind that, when oxidised, partially unhindered porphyrins can undergo $\mathrm{C}$-C coupling yielding porphyrin oligomers, ${ }^{13,14}$ this totally unsubstituted magnesium porphyrin should have unique redox reactivity.

We thus wish to report here our investigation of the 70 electrochemical and spectroelectrochemical behaviour of $\mathbf{1}$, with a particular emphasis on its oxidative reactivity, in relation to the mechanism of anodic polymerisation.

\section{Results}

\section{Synthesis of MgP}

751 was synthesised according to the Lindsey procedure. ${ }^{7,8}$ During the course of the synthesis, the precursor 1formyldipyrromethane $\mathbf{2}$ was purified by column chromatography protected from the light. Colourless crystals of 2 suitable for X-ray crystallography were grown in the dark 
from slow diffusion of $n$-pentane in a solution of 2 in dichloromethane. The crystallographic structure reveals two types of interactions in the crystal (Fig. 1).

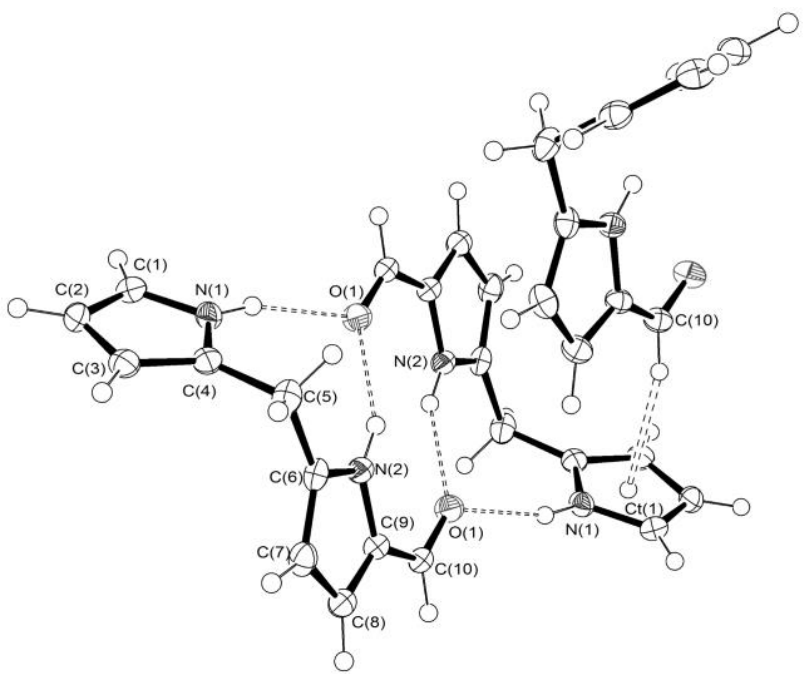

${ }_{5}$ Fig. 1 Ortep ${ }^{15}$ view of three 1-formyldipyrromethane (2) asymmetric units. The thermal ellipsoids are at the 50\% probability level. Hydrogen bonds and $\mathrm{CH}^{\cdots} \pi$ interactions are indicated by dashed lines.

In the asymmetric unit, the angle between two pyrrole rings is $63.85(6)^{\circ} .2$ exhibits two intermolecular hydrogen bonds ${ }_{10}(\mathrm{~N}(1)-\mathrm{H} . . \mathrm{O}(1)=2.01 \AA, \mathrm{N}(2)-\mathrm{H} \ldots \mathrm{O}(1)=2.05 \AA$ ) forming a dimer in the crystal as has been previously observed for dipyrrone ${ }^{16}$ or bilirubin ${ }^{17}$. These hydrogen bonds can account for the particularly highfield chemical shift of the aldehyde hydrogen atom $\left(9.26 \mathrm{ppm}\right.$ in $\mathrm{CDCl}_{3}, 300 \mathrm{MHz}$ in our 15 conditions, see also reference ${ }^{18}$ ). More original for dipyrrole molecules is the fact that the stability of the crystal is also ensured by $\mathrm{CH}^{\cdots} \pi$ interactions between $\mathrm{H}(10)$ from the aldehyde and the $\alpha$-unsubstituted pyrrole unit defined by centroid $\mathrm{Ct}(1)(\mathrm{C}(10)-\mathrm{Ct}(1)=3.4721(6) \AA ⿻ \mathrm{~A}, \mathrm{H}(10)-\mathrm{Ct}(1)=$ $\left.{ }_{20} 2.5639(6) \AA, \mathrm{C}(10)-\mathrm{H}(10)-\mathrm{Ct}(1)=160.1(5)^{\circ}\right)$.

\section{Electrochemistry}

The electrochemical behaviour of $\mathbf{1}$ was examined in dichloromethane with $0.1 \mathrm{~mol} \mathrm{~L}^{-1}$ TBAP as supporting electrolyte (available potential range : -2.2 to $1.8 \mathrm{~V} v s$. SCE).

${ }_{25}$ As outlined above, voltammetric data for $\mathbf{1}$ have previously been published, but few details were given. Indeed, only the first oxidation ${ }^{9,10}$ potential $E\left(\mathrm{ox}_{1}\right)_{1 / 2}$ * and the difference $E\left(\operatorname{ox}_{1}\right)_{1 / 2}-E\left(\operatorname{red}_{1}\right)_{1 / 2}$ were reported. ${ }^{11}{ }^{\star}$ Particularly, the cyclic voltammogram was not reproduced in any case.

30 The cyclic voltammogram of 1 recorded at $v=100 \mathrm{mV} \mathrm{s}^{-1}$ is presented in Fig. 2 (solid line) including both initial positive and negative potential directions. In the positive potential direction, two well defined peaks appear $\left(E_{\mathrm{p}, \mathrm{A}^{\prime}}=\right.$ $0.69 \mathrm{~V}$ and $\left.E_{\mathrm{p}, \mathrm{B}},=1.09 \mathrm{~V}\right)$. The first step seems to be nearly 35 reversible (system $\mathrm{A} / \mathrm{A}^{\prime}: i_{\mathrm{p}, \mathrm{A}^{\prime}} / i_{\mathrm{p}, \mathrm{A}} \sim 1$, according to the empirical Nicholson formula), but the second step is not (no prominent peak B facing peak B' in the backward scan). In the negative potential direction, the current response is not so straightforward. Two wide, ill-defined and poorly irreversible ${ }_{40}$ peaks are located near the solvent discharge $\left(E_{\mathrm{p}, \mathrm{E}} \sim-1.55 \mathrm{~V}\right.$ and $\left.E_{\mathrm{p}, \mathrm{F}}=-1.81 \mathrm{~V}\right)$.

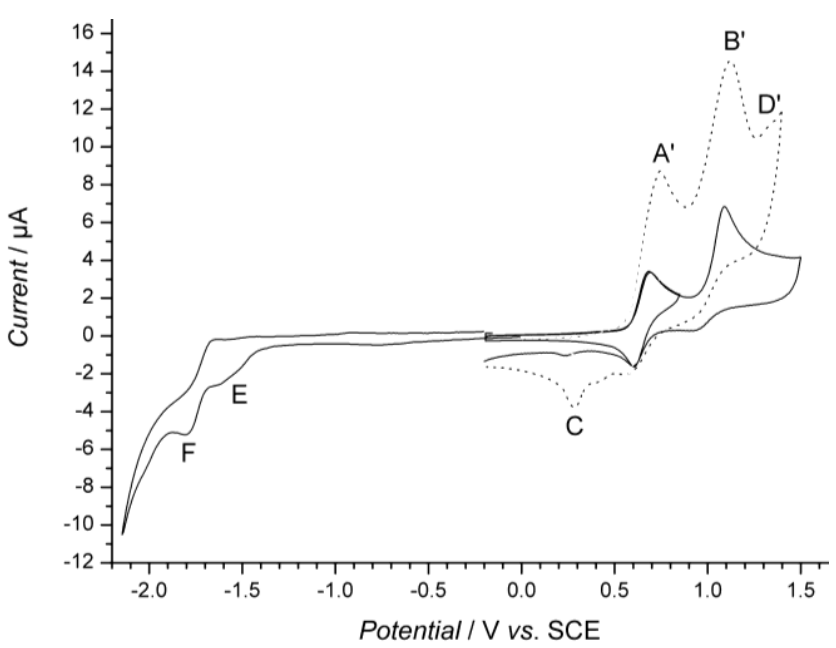

Fig. 2 Cyclic voltammograms of $\mathbf{1}$ in $\mathrm{CH}_{2} \mathrm{Cl}_{2}$ with TBAP $0.1 \mathrm{M}$. 45 Concentration: $5 \times 10^{-4}$ (solid line) and $10^{-3} \mathrm{M}$ (dotted line); WE: Pt $\emptyset=2$ $\mathrm{mm}$, scan rate: $v=100 \mathrm{mV} \mathrm{s}^{-1}$; initial potential $=-0.20 \mathrm{~V}$.

Usually, metalloporphyrins with a non-electroactive metal like $\mathrm{Mg}$ afford two ring centred reductions and two ringcentred oxidations for the respective formation of the $\pi$-anion 50 radical and $\pi$-dianion and the $\pi$-cation radical and $\pi$ dication. ${ }^{12}$ The very common diagnostic criteria for purely macrocycle concerned electron transfers (ETs) are the experimentally determined HOMO-LUMO gap, the potential difference between the first and the second oxidations, and the ${ }_{55}$ difference between the first and second reductions. Table 1 shows that the values measured for $\mathrm{MgP}$ are close to those found in the OEP and TPP series. It can thus be concluded that, in $\mathrm{MgP}$, the electron transfers as primary steps only affects the macrocycle.

60 With the most common porphyrins (TPP or OEP, for instance), these ET steps are essentially reversible. The net deviation of $\mathrm{MgP}$ from this ideal behaviour stems from the high reactivity of the electrogenerated species, as expected for this totally unprotected macrocycle. Particularly, 65 oligomerisation and polymerisation processes were expected. Accordingly, we observed that repetitive oxidative scans lead to a black/violet deposit on the electrode surface together with a progressive evolution of the cyclic voltammogram (peak broadening, baseline increase). However, we assume that this 70 evolution is not effective on the time scale of a single scan, so that completely formed oligomeric species do not interfere with the collected current, but oligomerisation/polymerisation intermediates do, as will be shown below. From a closer examination of the positive scan initiated voltammogram, 75 other particularities are noted (Fig. 2). Firstly, peak B' is clearly higher than $\mathrm{A}^{\prime}\left(i_{\mathrm{p}, \mathrm{B}} / i_{\mathrm{p}, \mathrm{A}^{\prime}} \sim 1.7\right.$ at $\left.100 \mathrm{mV} \mathrm{s}^{-1}\right)$. Moreover, in Fig. 2, B' looks like more symmetrical and sharper than A'. Tentatively, we propose that the cation radical can adsorb or depose on the electrode surface, but in a 80 rather slow process, so that B' arises from oxidation of both adsorbed and diffusive $\mathrm{MgP}^{\bullet+}$ species (Scheme 1), explaining that the shape of the peak is intermediate between diffusion 
Table 1 Potential characteristics of MgP and expected values for purely macrocycle concerned ETs

\begin{tabular}{cccc} 
& $\mathrm{E}\left(\mathrm{ox}_{1}\right)_{1 / 2}-\mathrm{E}\left(\mathrm{red}_{1}\right)_{1 / 2}(\mathrm{~V})$ & $\mathrm{E}\left(\mathrm{ox}_{2}\right)_{1 / 2}-\mathrm{E}\left(\mathrm{ox}_{1}\right)_{1 / 2}(\mathrm{~V})$ & $\mathrm{E}\left(\mathrm{red}_{1}\right)_{1 / 2}-\mathrm{E}\left(\mathrm{red}_{2}\right)_{1 / 2}(\mathrm{~V})$ \\
\hline Diagnostic criterion $^{19}$ & $2.15 \pm 0.15$ & $0.29 \pm 0.05$ & $0.42 \pm 0.05$ \\
$\mathrm{MgP}$ & 2.17 & 0.40 & $\sim 0.26$ \\
\hline
\end{tabular}

and adsorption:

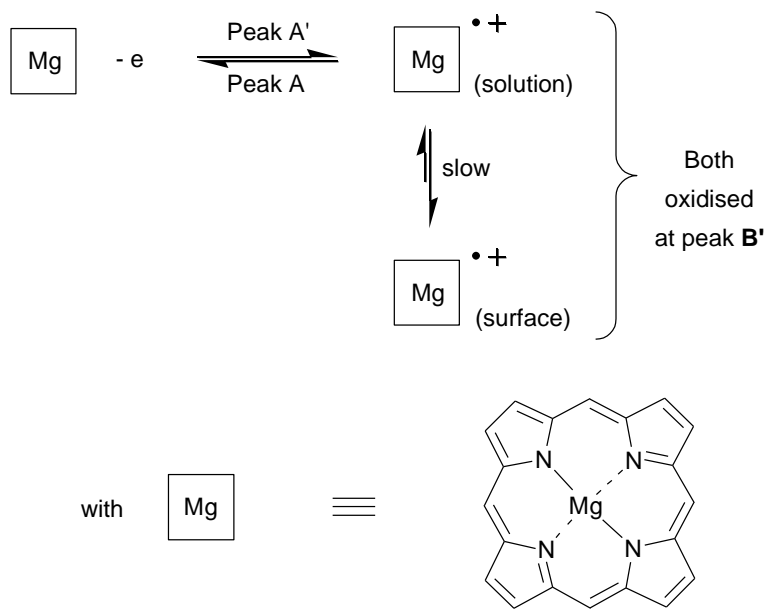

Scheme 1

Accordingly, $i_{\mathrm{p}, \mathrm{A}^{\prime}}$ varies linearly with $v^{1 / 2}$, as a pure diffusion current, but $i_{\mathrm{p}, \mathrm{B}}$, does not.

Additional details are noted in Fig. 2, particularly a weak peak (named C) at $E_{\mathrm{p}}=0.24 \mathrm{~V} v s . \mathrm{SCE}$ at $100 \mathrm{mV} \mathrm{s}^{-1}$. We 10 verified that this peak does not appear if the potential scan is inverted after $\mathrm{A}^{\prime}$, so that $\mathrm{C}$ must be assigned to a species resulting from the chemical evolution of the dication $\mathrm{MgP}^{2+}$.

Fig. 2 illustrates the effect of concentration on the oxidative behaviour of $\mathrm{MgP}$. Doubling the concentration induces 15 dramatic changes in the voltammetric trace of $\mathrm{MgP}$. Most obviously, a net increase in peak $\mathrm{C}$ is observed. The shape of this peak is now clearly symmetrical, denoting that the corresponding electroactive species is either adsorbed or deposited on the electrode surface. Additionally, peak $\mathrm{C}$ is 20 accompanied by a shoulder at $E_{\mathrm{p}} \sim 0.40 \mathrm{~V} v s$. SCE. For the doubled concentration (Fig. 2, dotted lines), new voltammetric trends also appear on the forward anodic scan : after peak B', the current no longer decreases (like at lower concentrations), but increases regularly, which indicates that the dication 25 chemical evolution product is oxidised in this potential zone.

In fact, these concentration dependant voltammetric features are of primary importance shining light on the early intermediates of the initiating steps of the electropolymerisation process. First, as the most immediate 30 information, these modifications testify to ET associated multiple order chemical processes. Another level of information concerns the identity of the evolution product. Basically, we evidenced this product to be reduced around 0.4 $\mathrm{V}$ and oxidised at a potential higher than $1.25 \mathrm{~V}$ which are 35 typical values for isoporphyrin-like species.

Isoporphyrins are porphyrins derivatives usually obtained by the addition of a nucleophile on the doubly oxidised porphyrin, i.e. the dication ${ }^{20,21}$ (Scheme 2):

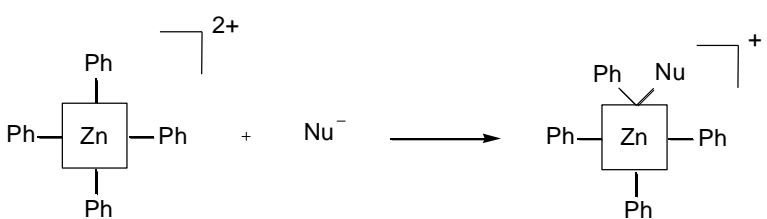

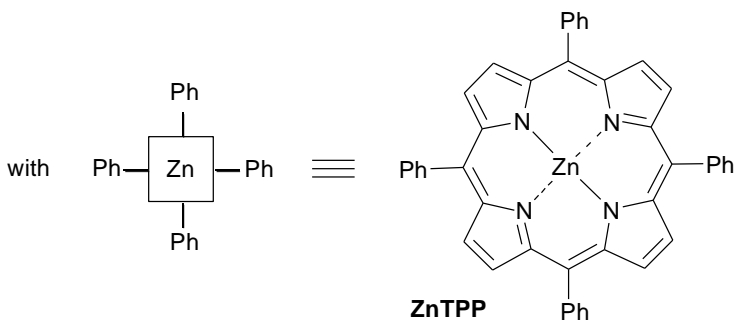

40 Scheme 2

In isoporphyrins, the conjugation is interrupted by the nucleophile added carbon atom, profoundly changing the electronic character. The electrochemical analysis of some of these compounds has been carried out. ${ }^{20,22}$ Isoporphyrins are 45 reversibly oxidised by one electron at potentials slightly higher than the corresponding porphyrin and irreversibly reduced by two-electrons at a potential which ranges from 0.2 to $0.6 \mathrm{~V}$ vs. SCE. Peaks $\mathrm{C}$ and $\mathrm{D}^{\prime}$ fall in these potential intervals and account for the electroactivity of such species.

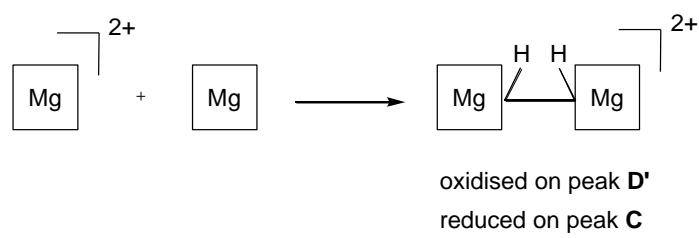

Scheme 3

To match the usual way of isoporphyrin formation, we suggest that the dication $\mathrm{MgP}^{2+}$ reacts with the nucleophilic neutral magnesium porphine, continuously flowing towards ${ }_{55}$ the electrode from the bulk of the solution (Scheme 3 ).

The reaction forms in fact a diprotonated derivative of the diporphine. Therefore, to account for such a species, at least at the time scale of this voltammetric experiment, deprotonation necessarily proceeds after C-C coupling. ${ }_{60}$ Deprotonation would be too slow to take effect on the time scale of the potential scan allowing voltammetric observation of this metastable intermediate of the early steps of the electropolymerisation process. 


\section{Spectroelectrochemistry}

In order to obtain more detailed information about the oxidation of the magnesium porphine, spectroelectrochemical experiments were performed in $\mathrm{CH}_{2} \mathrm{Cl}_{2}$ containing $0.1 \mathrm{~mol} \mathrm{~L}^{-1}$ 5 TBAP. Solutions of MgP were electrolysed on a large area platinum electrode $\left(E_{\text {app }}=0.70 \mathrm{~V}\right)$. In the course of the electrolysis, the UV-vis spectrum of the reacting solution was periodically picked up by means of an immersed probe. The electrolysis was stopped for an amount of electricity 10 corresponding to one electron transferred per molecule of $\mathrm{MgP}$ and the resulting crude solution directly analysed by RDE voltammetry, ESR spectroscopy and Maldi-TOF mass spectrometry.

In a first experiment, given the high molar extinction 15 coefficient of the MgP Soret band, ${ }^{7}$ the concentration was set rather low $\left([\mathrm{MgP}]_{\mathrm{i}}=1.8 \times 10^{-5} \mathrm{~mol} \mathrm{~L}^{-1}\right)$ so that the maximum absorbance fell into the readable spectrometer range. During the electrolysis, the colour changed from pink to light green/brown. The spectrum evolution is presented on Fig. 3.

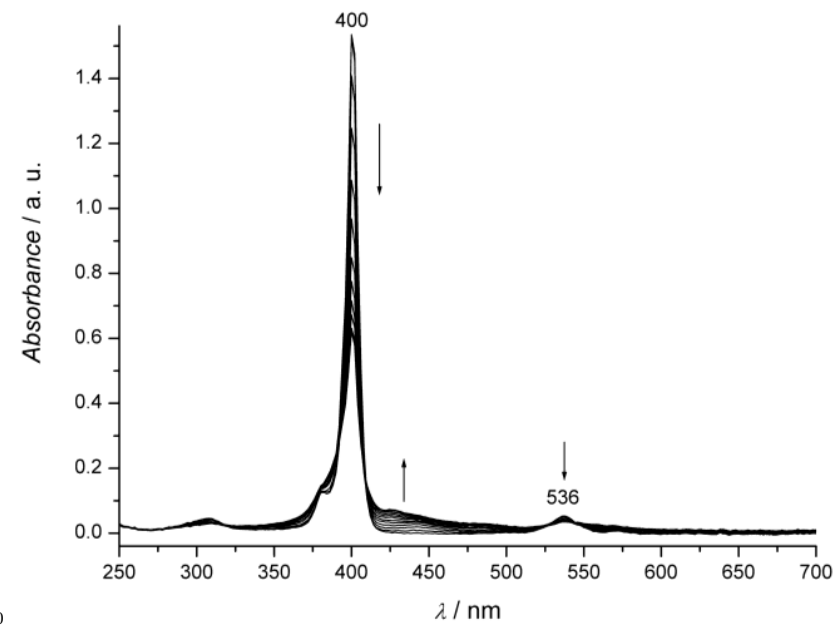

Fig. 3 Electrolysis of a $1.8 \times 10^{-5} \mathrm{M}$ solution of $\mathbf{1}$ followed by UV-Vis spectroscopy $\left(l=2 \mathrm{~mm}, 0.1 \mathrm{M}\right.$ TBAP in $\mathrm{CH}_{2} \mathrm{Cl}_{2}, E_{\text {app }}=0.70 \mathrm{~V} v \mathrm{~s}$. SCE, 1 electron, WE: Pt wire).

It follows that the initial Soret band $\left(\lambda_{\max }=400 \mathrm{~nm} ; A_{\max }=\right.$ 25 1.535) did not undergo any shift, but a significant intensity decrease (down to $A_{\max }=0.622$ for one electron transferred).

To obtain a better resolution on the weaker bands of the UV-vis spectrum, electrolyses were also performed at higher concentrations. A representative evolution is displayed in Fig. ${ }_{30} 4 \mathrm{~A}$ for $[\mathrm{MgP}]_{i}=5 \times 10^{-4} \mathrm{~mol} \mathrm{~L}^{-1}$. Two major trends are noted: 1) the progressive decrease in the initial bands at $\lambda_{\max }=536$ $\mathrm{nm}$ (Q band) and $\lambda_{\max }=309 \mathrm{~nm}$; 2) the emergence of two new bands at 442 and $427 \mathrm{~nm}$, although these do not appear simultaneously. Indeed, the band at $442 \mathrm{~nm}$ is already present 35 at the very beginning of the electrolysis, grows progressively, reaches a maximum (time coordinate $\approx 70 \%$ of the electrolysis duration) and then slightly decreases. Comparatively, the band at $427 \mathrm{~nm}$ appears later (time coordinate $\approx 19 \%$ of the electrolysis duration), but grows continuously until the end of 40 the electrolysis. Finally, after one-electron transfer, several analyses were carried out. First, the crude solution was found to be ESR silent, attesting to the instability of the radical cation on the electrolysis time scale. Second, the electrolysed solution exhibited almost no response by RDE voltammetry, 45 indicating that no more electroactive species survived in solution. In relation to this observation, a black/violet deposit was observed on the platinum working electrode together with a dark-coloured precipitate suspended in solution, all in all giving evidence of the poor solubility of the 50 electrosynthesised products.

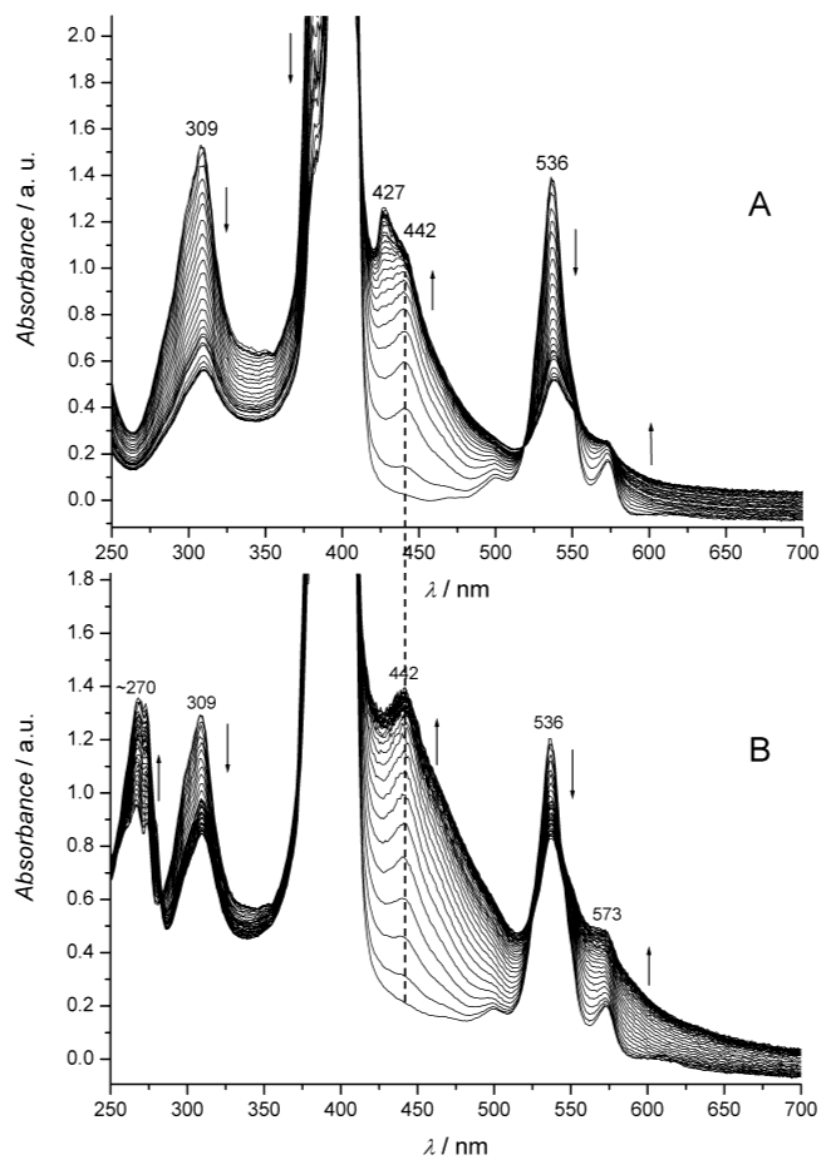

Fig. 4 Electrolysis of a $5 \times 10^{-4} \mathrm{M}$ solution of 1 without (A) or with (B) 2 equiv. of 2,6-lutidine followed by UV-Vis spectroscopy $(l=2 \mathrm{~mm}, 0.1 \mathrm{M}$ TBAP in $\mathrm{CH}_{2} \mathrm{Cl}_{2}, E_{\text {app }}=0.70 \mathrm{~V}$ vs. SCE, -1 electron, WE: Pt wire).

55 Still in the case of this one-electron electrolysis, the MALDI-TOF mass spectrum of the reacting mixture (Fig. 5A) revealed the formation of oligomers up to the pentamer. ${ }^{\S}$ Additionally, the oligomer formation was accompanied by extensive demetallation since, in all the collected fragments, 60 at least one magnesium atom was missing ( \pm 22 mass gap for gain/loss for one $\mathrm{Mg}$ atom) compared to the corresponding fully metallated oligomer.

The occurrence of demetallation here is not surprising since it is well-known that magnesium porphyrins can react in such 65 a way in acidic media. ${ }^{23}$ In the context of electrochemically driven oligomerisation of $\mathrm{MgP}$, each bond formed between two porphyrin units releases two protons, as exemplified in the dimer formation (Scheme 4). Thus, as oxidation of $\mathrm{MgP}$ and, subsequently, oligomerisation are proceeding, the 70 electrolytic medium is becoming more and more acid causing progressive demetallation of the initial magnesium porphine 
and the magnesium containing oligomers. Like the free base porphine, ${ }^{24}$ the resulting demetallated species should be less soluble, and accordingly precipitate and thus stop the electrolysis for lack of oxidisable material in solution.
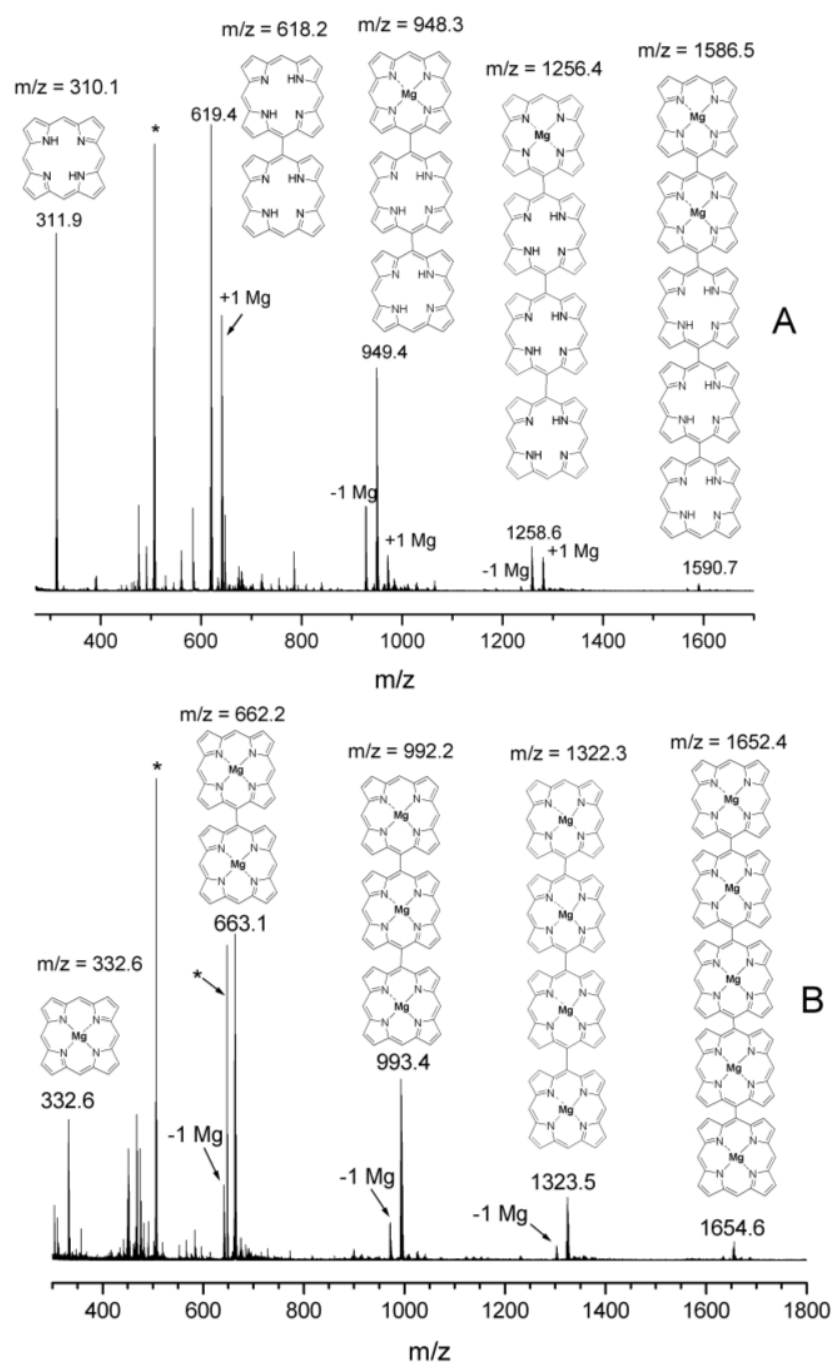

Fig. 5 MALDI-TOF mass spectra of the crude solution resulting from the electrolysis of a $5 \times 10^{-4} \mathrm{M}$ solution of 1 without (A) or with (B) 2 equiv. of 2,6-lutidine $\left(0.1 \mathrm{M}\right.$ TBAP in $\mathrm{CH}_{2} \mathrm{Cl}_{2}, E_{\text {app }}=0.70 \mathrm{~V}$ vs. SCE, - 1 electron, WE: Pt wire). The peaks marked by asterisks correspond to 10 matrix impurities. Magnesium porphine oligomers are drawn in a linear fashion for aesthetic reasons; zigzag or branched chains can also be envisaged.

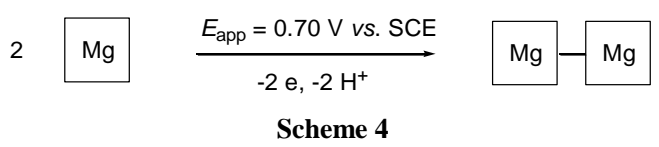

15 To circumvent this demetallation process, an excess of 2,6lutidine (2.0 equivalents) as a base was added to the initial solution and the electrolysis was repeated in the same experimental conditions (Fig. 4B). The initial pink solution turned red/yellow/brown. A similar evolution of the UV-Vis 20 spectrum was observed but without the $427 \mathrm{~nm}$ band (Fig. 4A). After one-electron-transfer, no precipitate was observed in the resulting solution although a black/purple solid was still deposited on the platinum working electrode. Contrary to the experiment without a base, the RDE voltammetry 25 measurements confirmed the existence of redox-active products in solution with an anodic current response in the same potential range as $\mathrm{MgP}$. Additionally, a clear reduction signal was observed at $\sim-0.6 \mathrm{~V}$ corresponding to the protonated 2,6-lutidine reduction. Hence, due to the 30 characteristic potential position of this signal, the base may act here as a proton probe, allowing examination of the proton release during the electrolysis.

Maldi-Tof analysis corroborated the existence of almost totally metallated oligomers (Fig. 5B) although minor peaks 35 were still present, the result of the loss of a single magnesium atom from the fully metallated oligomers. Retrospectively, and correlating these Maldi-tof observations, it follows that, in the UV-visible evolution, the $442 \mathrm{~nm}$ band must be associated with the fully metallated dimer and the $427 \mathrm{~nm}$ 40 with the partially or totally demetallated dimer.

The question of dimer formation by chemical oxidation of metalloporphyrins has been the focus of numerous studies. In this reaction, the most usual oxidant is a silver(I) salt. ${ }^{25}$ The coupling proceeds on condition that some peripheric positions 45 on the porphyrin ring are totally unhindered. Osuka discovered that the link between the porphyrin units (mesomeso or meso- $\beta$ ) could be selected thanks to the metal incorporated in the porphyrin ring. ${ }^{14} \mathrm{Mg}$ and $\mathrm{Zn}$ lead to mesomeso arrangements whereas $\mathrm{Cu}, \mathrm{Pd}$ and $\mathrm{Ni}$ favour the meso- $\beta$ 50 one. ${ }^{14}$ The $\beta, \beta^{\prime}$ configuration can also be synthesised, but not directly by way of the oxidative pathway. ${ }^{26}$ As a general rule, the absorption spectrum of the dimers presents two Soret bands of similar intensity. The band difference is a key argument in distinguishing between the different link types. 55 Among the numerous reports in the literature, for free base and zinc porphyrin dimers, the wavelength gap for $\beta, \beta^{\prime}$ and meso- $\beta$ dimers falls into the range of [9-19 nm $]^{14,26,27}$ or is not clearly resolved ${ }^{28}$ whereas meso-meso derivatives are characterised by a significantly larger interval, [31-40 $60 \mathrm{~nm}] .{ }^{13,29}$ In our case, it can be doubly argued that the $(\mathrm{MgP})_{2}$ dimer belongs to the meso-meso linked class because first, the Soret band difference is estimated at $35 \mathrm{~nm}^{\text {II }}$ and is clearly affiliated with the wide interval category and, second, the magnesium effect directs the reaction towards the meso-meso 65 link type.

This meso-meso link type may possibly be generalised to all the oligomer series. However, until now, no direct evidence of the meso-meso bond (e.g. NMR or crystallographic proof) have been obtained. As a matter of 70 fact, we did not succeed in separating the oligomers by means of classical column chromatography or even by size exclusion chromatography. New synthetic strategies are presently under investigation in the hope of obtaining individual access to the oligomeric compounds.

\section{${ }_{75}$ Discussion}

\section{Analytical methodology}

The electrochemical oxidation of $\mathrm{MgP}$ was explored according to two distinct experimental lines: 1) cyclic voltammetry; 2) controlled-potential electrolysis 
complemented by spectroscopic identification of the products

in solution. This analytical approach was adequate to the
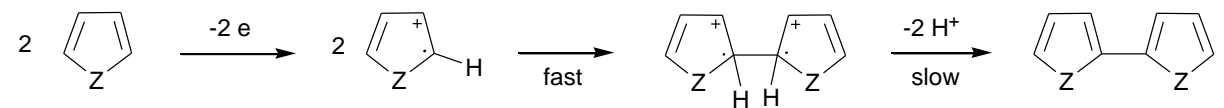

Pyrrole: $Z=\mathrm{NH}$

Thiophene: $Z$ = S

(B)
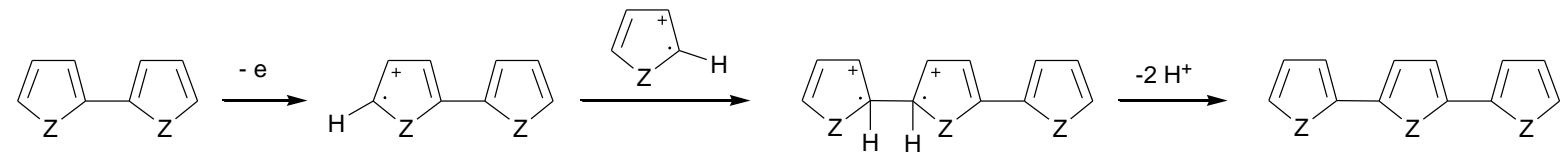

Scheme 5

5 purpose of this work, providing information at two complementary levels. Accordingly, in the dimension of space, cyclic voltammetry concerns species lying near the electrode or deposited on the surface whereas the spectroelectrolytic method is dedicated to species dispersed in solution. 10 Additionally, regarding the aspect of time scale in each method, cyclic voltammetry allowed to observe transient intermediates, whereas only definitively stable products can be characterised by the other method.

\section{Mechanistic information concerning electropolymerisation}

${ }_{15}$ Cyclic voltammetry. The electrochemical oxidation of $\mathrm{MgP}$ (1) gives sequential access to the corresponding $\pi$-cation radical and $\pi$-dication. In the studied range of concentration $s$ and scan rates (see Figure 2), the $\pi$-cation radical appears unreactive, contrary to the $\pi$-dication which is found to be 20 highly reactive. In fact, $\mathrm{MgP}^{2+}$ undergoes a fast reaction with the starting neutral $\mathrm{MgP}$ to afford a diprotonated diisoporphine, which can be observed voltammetrically, since its thermodynamically favoured deprotonation takes longer than the experiment time window. These results find echoes in 25 the mechanism of anodic polymerisation of the extensively studied pyrrole or thiophene (Scheme 5). ${ }^{30}$

With MgP as with pyrrole or thiophene, access to the "diprotonated" dimer is provided by successively an electron transfer step followed by $\mathrm{C}-\mathrm{C}$ coupling, before deprotonation 30 operates (sequence $\mathrm{A}$ in Scheme 5). A marked difference lies in the stability of the respective cation radical which is much more unstable when issued from pyrrole or thiophene. apparent stability of $\mathrm{MgP}^{\cdot+}$ is in accordance with its less electrophilic character due to a more extended $\pi$-conjugation.

35 As a consequence of this difference in reactivity, in the case of pyrrole or thiophene, the "diprotonated" dimer arises from homocoupling (cation radical versus cation radical) as opposed to heterocoupling (dication versus neutral $\mathrm{MgP}$ ) in the voltammetry of $\mathbf{1}$.

40 Spectroelectrolysis. It was first demonstrated above that $\mathrm{MgP}^{\cdot+}$ is reactive on a longer experiment time scale. Indeed, its selective generation at the applied electrolysis potential results in the formation of the oligoporphines. Although we have no sufficient experimental proof, the same mechanistic 45 pathway observed in pyrrole or thiophene seems likely (Scheme 5, sequence A).

Identified in the electrolysis product mixture, the triporphine necessarily derives from one monomer and one dimer unit. As a possible mechanism, sequence B seems to be 50 reasonable, as it is built on similar steps as sequence $\mathrm{A}$, i.e. electron transfer, followed by CR-CR coupling, and then deprotonation. The same mechanism may also be associated with the superior homologues (tetraporphine, pentaporphine, ...). In a more general sense, it may be the principle 55 underlying polymer chain elongation at the electrode.

\section{Experimental}

\section{Crystallography}

X-ray Crystallographic Study. Crystal data for $\left[\mathrm{C}_{10} \mathrm{H}_{10} \mathrm{~N}_{2} \mathrm{O}\right]$, colourless prism crystal of dimension $0.45 \times 0.42 \times 0.40 \mathrm{~mm}$, ${ }_{60} M=174.20 \mathrm{~g} \mathrm{~mol}^{-1}$, monoclinic, space group $\mathrm{P} 2{ }_{1} / \mathrm{c}, \mathrm{Z}=4$, a = 11.8435(5) $\AA, \mathrm{b}=6.9555(2) \AA, \mathrm{c}=11.1256(4) \AA, \beta=$ 106.470(1) ${ }^{\circ}, \mathrm{V}=878.89(6) \AA^{3}, \mathrm{Dx}=1.317 \mathrm{~g} \mathrm{~cm}^{-3}, \mathrm{~T}=115(2)$ $\mathrm{K}, \mathrm{F}(000)=368$, Mo- $\mathrm{K}_{\alpha}$ radiation $(\lambda=0.71073 \AA), \mu=0.088$ $\mathrm{mm}^{-1}, 3559$ reflections measured in the range $3.43^{\circ} \leq \theta \leq$ ${ }_{65} 27.48^{\circ}$, with 1985 being unique $\left(R_{\text {int }}=0.0301\right)$ which were used in all calculations. The structure was solved by direct methods and refined using full-matrix least-squares on $F^{2}$ to $\mathrm{R} 1=0.0404, \mathrm{~S}=1.047$, for 1985 reflections with $I>2 \sigma(I)$ and 119 refined parameters, $w R 2=0.1087$ (all data).

${ }_{70} \mathrm{X}$-ray equipment and refinement. Diffraction data were collected on a Nonius KappaCCD diffractometer equipped with a nitrogen jet stream low-temperature system (Oxford Cryosystems). The X-ray source was graphite-monochromated Mo$K_{\alpha}$ radiation $(\lambda=0.71073 \AA)$ from a sealed tube. The lattice 75 parameters were obtained by least-squares fit to the optimised setting angles of the entire set of collected reflections. No significant temperature drift was observed during data collection. Data were reduced by using the DENZO ${ }^{31}$ software without applying absorption corrections; the missing absorption 80 corrections were partially compensated by means of the data scaling procedure in the data reduction. The structure was solved by direct methods using the SIR $92^{32}$ program. Refinements were carried out by full-matrix least-squares on $F^{2}$ using the SHELXL9 $7^{33}$ program on the complete set of reflections. Aniso85 tropic thermal parameters were used for non-hydrogen atoms. All $\mathrm{H}$ atoms, on carbon atom, were placed at calculated positions using a riding model with $\mathrm{C}-\mathrm{H}=0.95 \AA$ (aromatic), $0.99 \AA$ (methylene) with $U_{\text {iso }}(\mathrm{H})=1.2 U_{\text {eq }}\left(\mathrm{CH}_{2}, \mathrm{CH}\right) . \mathrm{H}$ atoms on nitrogen atoms were located in the Fourier difference maps. ${ }_{90}$ Their positional parameters were refined freely with $U_{\text {iso }}(\mathrm{H})=$ $1.2 U_{\mathrm{eq}}(\mathrm{N})$.

\section{Reagents and instrumentation}

1-formyl-dipyrromethane $\mathbf{2}$ and magnesium porphine $\mathbf{1}$ were synthesised according to known procedures. ${ }^{7}$ The data $\left({ }^{1} \mathrm{H}\right.$ 
NMR, ${ }^{13} \mathrm{C}$ NMR, absorption, and Maldi-Tof) were consistent with those obtained in reference. ${ }^{7}$ Dichloromethane (Carlo Erba, $99.5 \%$ for analysis) was distilled on $\mathrm{P}_{2} \mathrm{O}_{5}$ just before use. Tetra- $n$-butylammonium perchlorate (TBAP) was 5 purchased from Fluka (electrochemical grade) and used as received. 2,6-lutidine $(\geq 99 \%)$ was purchased from SigmaAldrich and used as received.

All manipulations were performed using Schlenk techniques in an atmosphere of dry oxygen-free argon. The 10 supporting electrolyte was degassed under vacuum before use and then dissolved to a concentration of $0.1 \mathrm{~mol} \mathrm{~L}^{-1}$. Voltammetric analyses were carried out in a standard threeelectrode cell, with an EG\&G Princeton Applied Research (PAR) Model 263 A potentiostat, connected to an interfaced 15 computer that employed Electrochemistry Power Suite software. The reference electrode was a saturated calomel electrode (SCE) separated from the solution by a sintered glass disk. The auxiliary electrode was a platinum wire separated from the solution by a sintered glass disk. For all

20 voltammetric measurements, the working electrode was a platinum electrode $(\varnothing=2 \mathrm{~mm})$. In these conditions, when operating in $\mathrm{CH}_{2} \mathrm{Cl}_{2}$, the formal potential for the ferrocene $(+/ 0)$ couple was found to be $+0.46 \mathrm{~V}$ vs. the SCE. Bulk electrolyses were performed in a cell with three compartments 25 separated with glass frits of medium porosity with an Amel 552 potentiostat coupled with an Amel 721 electronic integrator and followed in situ by an UV-Vis immersion probe (Hellma, $l=2 \mathrm{~mm}$ ) connected through fibre optic to a Varian UV-visible spectrophotometer Cary 50 scan. A platinum wire 30 spiral $(l=53 \mathrm{~cm}, \varnothing=1 \mathrm{~mm})$ was used as the working electrode, a platinum plate as the counter electrode and a saturated calomel electrode as the reference electrode.

Mass spectra were obtained on a Bruker ProFLEX III spectrometer (MALDI-TOF) using dithranol as the matrix.

\section{${ }_{35}$ Conclusions}

The detailed electrochemical characterisation of magnesium(II) porphine in dichloromethane is presented here for the first time.

On the time scale of cyclic voltammetry, the 40 electrogenerated $\pi$-cation radical could be reversibly reduced to the neutral product contrary to the $\pi$-dication, which may react with the neutral $\mathrm{MgP}$ yielding an isoporphine intermediate.

On a longer time scale, i.e. during electrolysis experiment, 45 the abstraction of one electron at an applied potential corresponding to the $\pi$-cation radical generation leads to the formation of porphine oligomers in solution. The proposed mechanism for the oligomer chain elongation is similar to that of the well-known pyrrole electropolymerisation one, with a 50 fast $\pi$-cation radical/ $\pi$-cation radical coupling as an initial step, followed by a slow deprotonation of this intermediate.

Our efforts are now focused on the separation, purification and characterisation of the $\mathrm{MgP}$ oligomers which may have interesting applications in molecular devices such as nonlinear 55 optical devices, sensors or photoactive species...

\section{Acknowledgements}

The authors would like to thank the Centre National de la Recherche Scientifique, the Conseil Régional de Bourgogne and the Université de Bourgogne for financial support.

60 The authors are grateful to Sophie Dalmolin and Céline Duriez for technical support, and Mary Bouley for her nice and priceless expertise.

\section{Notes and references}

${ }^{a}$ Institut de Chimie Moléculaire de l'Université de Bourgogne, Université 65 de Bourgogne, CNRS UMR 5260, 9 avenue Alain Savary, 21078 Dijon Cedex, France. Fax: (+33) 380396065; Tel: (+33) 380399125; E-mail: charles.devillers@u-bourgogne.fr; dominique.lucas@u-bourgogne.fr

$\dagger$ Electronic Supplementary Information (ESI) available: UV-visible spectroscopy characterisation of $(\mathrm{MgP})_{2}$ dimer and Maldi-Tof mass 70 spectrometry characterisation measured on the sample issued from the UV-visible analysis. See DOI: 10.1039/b000000x/

$\ddagger$ According to the Frontier Scientific Catalog in 2009, the price for 10 $\mathrm{mg}$ of porphine is 105 US dollars.

+ $E\left(\mathrm{ox}_{1}\right)_{1 / 2}=+0.68 \mathrm{~V} v \boldsymbol{s}$. $\mathrm{SCE}^{10}$ in similar conditions as ours.

$75 E\left(\mathrm{ox}_{1}\right)_{1 / 2}-E\left(\mathrm{red}_{1}\right)_{1 / 2}=+2.1 \mathrm{~V}$ in reference ${ }^{11}$.

$\delta$ A complete and exhaustive study of this intriguing oxidative polymerisation as well as the characterisation of the resulting material will be soon reported. ${ }^{34}$

$\S$ We verified by an independent analysis of $\mathbf{1}$ that the oligomers couldn't 80 be formed from the monomer by laser excitation/irradiation.

II According to preliminary results, the UV-Vis spectrum of $(\mathrm{MgP})_{2}$ dimer exhibits two well defined Soret bands at 405 and $440 \mathrm{~nm}$ in $\mathrm{CH}_{2} \mathrm{Cl}_{2}$ (see ESI).

85 || The lifetime is measured at $30 \mathrm{~ms}$ for the radical cation generated from pyrrole while roughly estimated in the order of the $s$ for $\mathrm{MgP}^{++} .35$

1. H. Imahori, M. Kimura, K. Hosomizu, T. Sato, T. K. Ahn, S. K. Kim, D. Kim, Y. Nishimura, I. Yamazaki, Y. Araki, O. Ito and S. Fukuzumi, Chem. Eur. J., 2004, 10, 5111; L. Wei, K. Padmaja, W. J.

90 Youngblood, A. B. Lysenko, J. S. Lindsey and D. F. Bocian, J. Org. Chem., 2004, 69, 1461; C. Bucher, C. H. Devillers, J.-C. Moutet, G. Royal and E. Saint-Aman, Chem. Commun., 2003, 888; E. Song, C. Shi and F. C. Anson, Langmuir, 1998, 14, 4315.

2. J. Bohandy and B. F. Kim, J. Chem. Phys., 1980, 73, 5477; J. 95 Bohandy and B. F. Kim, J. Chem. Phys., 1982, 76, 1180; C. Shi, B. Steiger, M. Yuasa and F. C. Anson, Inorg. Chem., 1997, 36, 4294; S. W. Wu, N. Ogawa, G. V. Nazin and W. Ho, J. Phys. Chem. C, 2008, 112, 5241; S. A. Krasnikov, J. P. Beggan, N. N. Sergeeva, M. O. Senge and A. A. Cafolla, Nanotechnology, 2009, 20, 135301; S. 100 Yoshimoto, J. Inukai, A. Tada, T. Abe, T. Morimoto, A. Osuka, H. Furuta and K. Itaya, J. Phys. Chem. B, 2004, 108, 1948.

3. J. Braun, R. Schwesinger, P. G. Williams, H. Morimoto, D. E. Wemmer and H.-H. Limbach, J. Am. Chem. Soc., 1996, 118, 11101.

4. K. Ono, M. Yoshizawa, T. Kato, K. Watanabe and M. Fujita, Angew. 105 Chem. Int. Ed., 2007, 46, 1803; A. Marcelli, P. Foggi, L. Moroni, C. Gellini, P. R. Salvi and I. J. Badovinac, J. Phys. Chem. A, 2007, 111, 2276.

5. P. M. Kozlowski, M. Z. Zgierski and P. Pulay, Chem. Phys. Lett., 1995, 247, 379; P. M. Kozlowski, A. A. Jarzęcki and P. Pulay, J. 110 Phys. Chem., 1996, 100, 7007; T. G. Spiro, P. M. Kozlowski and M. Z. Zgierski, J. Raman Spectrosc., 1998, 29, 869; P. M. Kozlowski, K. Wolinski and P. Pulay, J. Phys. Chem. A, 1999, 103, 420; J. Jusélius and D. Sundholm, J. Org. Chem., 2000, 65, 5233; M. Kamishima, M. Kojima and Y. Yoshikawa, J. Comput. Chem., 2001, 22, 835; T. 115 Vangberg, R. Lie and A. Ghosh, J. Am. Chem. Soc., 2002, 124, 8122; K. P. Jensen and U. Ryde, ChemBioChem, 2003, 4, 413; J. Šeda, J. V. Burda and J. Leszczynski, J. Comput. Chem., 2005, 26, 294; G. A. Peralta, M. Seth and T. Ziegler, Inorg. Chem., 2007, 46, 9111; I. Yanov, Y. Kholod, J. Leszczynski and J. J. Palacios, Chem. Phys. Lett., 2007, 445, 238; S. Welack, J. B. Maddox, M. Esposito, U. 
Harbola and S. Mukamel, Nano Lett., 2008, 8, 1137; I. Lanzo, N. Russo and E. Sicilia, J. Phys. Chem. B, 2008, 112, 4123.

6. P. Rothemund, J. Am. Chem. Soc., 1935, 57, 2010; P. Rothemund, J. Am. Chem. Soc., 1936, 58, 625; H. Fischer and W. Gleim, Justus

Liebigs Ann. Chem., 1936, 521, 157; U. Eisner and R. P. Linstead, J. Chem. Soc., 1955, 3742; G. D. Egorova, K. N. Solov'ev and A. M. Shul'ga, Zh. Obshch. Khim., 1967, 37, 357; S. Krol, J. Org. Chem., 1959, 24, 2065; U.S. Pat., 3579 533, 1971; F. R. Longo, E. J. Thorne, A. D. Adler and S. Dym, J. Heterocycl. Chem., 1975, 12, 1305; S. Neya, H. Yodo and N. Funasaki, J. Heterocycl. Chem., 1993, 30, 549; R. P. Bonar-Law, J. Org. Chem., 1996, 61, 3623; S. Taniguchi, H. Hasegawa, M. Nishimura and M. Takahashi, Synlett, 1999, 73; S. Neya and N. Funasaki, Tetrahedron Lett., 2002, 43, 1057; S. Neya, J. Quan, T. Hoshino, M. Hata and N. Funasaki,

15 Tetrahedron Lett., 2004, 45, 8629; S. Neya, J. Quan, M. Hata, T. Hoshino and N. Funasaki, Tetrahedron Lett., 2006, 47, 8731; I. Saltsman, I. Goldberg, Y. Balasz and Z. Gross, Tetrahedron Lett., 2007, 48, 239

7. D. K. Dogutan, M. Ptaszek and J. S. Lindsey, J. Org. Chem., 2007, $20 \quad 72,5008$.

8. D. K. Dogutan, M. Ptaszek and J. S. Lindsey, J. Org. Chem., 2008, 73, 6187.

9. F. J. Kampas, K. Yamashita and J. Fajer, Nature, 1980, 284, 40; J.-H. Fuhrhop, Porphyrins and Metalloporphyrins, Am. Elsevier, New York, 1968.

10. K. Yamashita, Chem. Lett., 1982, 11, 1085.

11. R. Schlözer and J.-H. Fuhrhop, Angew. Chem., Int. Ed. Engl., 1975, 14, 1975.

12. K. M. Kadish, K. M. Smith and R. Guilard, in The Porphyrin

30 Handbook, ed. K. S. K. M. Kadish, R. Guilard, Academic Press, 2000, vol. 8, Chap 55.

13. A. Osuka and H. Shimidzu, Angew. Chem., Int. Ed. Engl., 1997, 36, 135; N. Aratani, A. Takagi, Y. Yanagawa, T. Matsumoto, T. Kawai, Z. S. Yoon, D. Kim and A. Osuka, Chem. Eur. J., 2005, 11, 3389.

35 14. T. Ogawa, Y. Nishimoto, N. Yoshida, N. Ono and A. Osuka, Angew. Chem. Int. Ed., 1999, 38, 176.

15. L. J. Farrugia, J. Appl. Cryst, 1997, 30, 565.

16. M. T. Huggins and D. A. Lightner, Monatsh. Chem., 2001, 132, 203.

17. S. K. Dey and D. A. Lightner, J. Org. Chem., 2008, 73, 2704.

40 18. M. Ptaszek, B. E. McDowell and J. S. Lindsey, J. Org. Chem., 2006, 71, 4328.

19. J.-H. Fuhrhop, K. M. Kadish and D. G. Davis, J. Am. Chem. Soc., 1973, 95, 5140.

20. W. R. Fawcett, M. Fedurco, K. M. Smith and H. Xie, J. Electroanal.

45 Chem., 1993, 354, 281; R. Guilard, N. Jagerovic, A. Tabard, C. Naillon and K. M. Kadish, J. Chem. Soc., Dalton Trans., 1992, 1957; A. S. Hinman, B. J. Pavelich, A. E. Kondo and S. Pons, J. Electroanal. Chem., 1987, 234, 145.

21. H. Xie and K. M. Smith, Tetrahedron Lett., 1992, 33, 1197.

50 22. K. M. Kadish and R. K. Rhodes, Inorg. Chem., 1981, 20, 2961.

23. J. S. Lindsey and J. N. Woodford, Inorg. Chem., 1995, 34, 1063.

24. D.-F. Shi and R. T. Wheelhouse, Tetrahedron Lett., 2002, 43, 9341.

25. N. Yoshida, N. Aratani and A. Osuka, Chem. Commun., 2000, 197.

26. G. Bringmann, D. C. G. Götz, T. A. M. Gulder, T. H. Gehrke, T.

55 Bruhn, T. Kupfer, K. Radacki, H. Braunschweig, A. Heckmann and C. Lambert, J. Am. Chem. Soc., 2008, 130, 17812.

27. Y. Deng, C. K. Chang and D. G. Nocera, Angew. Chem. Int. Ed., $2000,39,1066$.

28. H. Uno, Y. Kitawaki and N. Ono, Chem. Commun., 2002, 116; J. B.

60 Paine_III, D. Dolphin and M. Gouterman, Can. J. Chem., 1978, 56, 1712.

29. K. Susumu, T. Shimidzu, K. Tanaka and H. Segawa, Tetrahedron Lett., 1996, 37, 8399; L.-M. Jin, L. Chen, J.-J. Yin, C.-C. Guo and Q. Y. Chen, Eur. J. Org. Chem., 2005, 3994; L.-A. Fendt, H. Fang, M. E. Plonska-Brzezinska, S. Zhang, F. Cheng, C. Braun, L. Echegoyen and F. Diederich, Eur. J. Org. Chem., 2007, 4659; T. Hasobe, H. Imahori, HirokoYamada, T. Sato, K. Ohkubo and S. Fukuzumi, Nano Lett., 2003, 3, 409; C.-A. Wu, C.-L. Chiu, C.-L. Mai, Y.-S. Lin and C.-Y. Yeh, Chem. Eur. J., 2009, 15, 4534; M. O. Senge and X. Feng, 70 Tetrahedron Lett., 1999, 40, 4165; M. O. Senge and X. Feng, J.
Chem. Soc., Perkin Trans. I, 2000, 3615; R. G. Khoury, L. Jaquinod and K. M. Smith, Chem. Commun., 1997, 1057.

30. M. Zhou, M. Pagels, B. Geschke and J. Heinze, J. Phys. Chem. B, 2002, 106, 10065; M. Zhou and J. Heinze, J. Phys. Chem. B, 1999,

75 103, 8443; M. Zhou and J. Heinze, J Phys. Chem. B, 1999, 103, 8451; L. Guyard, P. Hapiot and P. Neta, J. Phys. Chem. B, 1997, 101, 5698; C. P. Andrieux, P. Audebert, P. Hapiot and J.-M. Savéant, J. Phys. Chem. B, 1991, 95, 10158.

31. Z. Otwinowski, W. Minor and C. W. Carter_Jr., Methods in Enzymology, 1997, 276, 307-326.

32. A. Altomare, G. Cascarano, C. Giacovazzo and A. Guagliardi, J. Appl. Crystallogr., 1993, 26, 343.

33. G. Sheldrick, Acta Cryst., Sect. A, 2008, 64, 112; G. M. Sheldrick, Editon edn., University of Göttingen, Göttingen, Germany, 1997.

85 34. M. A. Vorotyntsev, D. V. Konev, C. H. Devillers, I. Bezverkhyy and O. Heintz, Chem. Commun., submitted.

35. C. P. Andrieux, P. Audebert, P. Hapiot and J.-M. Savéant, J. Am. Chem. Soc., 1990, 112, 2439. 